\title{
FORECASTING THE ELECTRIC CONSUMPTION OF OBJECTS USING ARTIFICIAL NEURAL NETWORKS
}

\author{
$F A$ Hoshimov $^{1}$, I I Bakhadirov ${ }^{1}$, A A Alimov ${ }^{1}$, M T Erejepov ${ }^{2}$ \\ ${ }^{1}$ Tashkent State Technical University named after Islam Karimov, 100095, Uzbekistan, Tashkent, University St. 2A \\ ${ }^{2}$ Karakalpak State University, 230100, Uzbekistan, Nukus, Ch. Abdirov St.1
}

\begin{abstract}
The possibility of using artificial neural networks of the Matlab mathematical package for predicting the power consumption of objects is considered, the parameters that affect the power consumption are studied.
\end{abstract}

\section{Introduction}

The task of planning electricity consumption has always been important for the process of purchasing and using electricity. In recent years, it has become very acute in connection with the reform of the Uzbek electric power industry. The rules for the functioning of retail markets establish the obligation of consumers to accurately plan the volumes of electricity consumption and establish their responsibility for consumption in a larger or smaller volume than planned. Deviation in electricity consumption of more than 3\% from the planned one leads to additional costs. The more serious the deviations, the larger the amount the company is forced to pay for the inconsistencies.

\section{Main part}

Thus, the energy service of the enterprise is faced with the difficult task of drawing up a reliable application for electricity consumption. Recently, in connection with the development of artificial intelligence technologies, artificial neural networks (ANNs) are attracting more and more attention from specialists involved in forecasting electricity consumption [1-6].

Artificial neural networks (ANNs) are mathematical models, as well as their software or hardware implementations, built on the principle of the organization and functioning of biological neural networks - networks of nerve cells of a living organism.

ANNs are a system of simple processors (artificial neurons) connected and interacting with each other. Such processors are usually quite simple, especially when compared to the processors used in personal computers. Each processor on such a network deals only with signals that it receives periodically and signals that it periodically sends to other processors. And yet, when connected in a large enough network with controlled interactions, such locally simple processors together are capable of performing rather complex tasks [1-11].

Recently, in connection with the development of artificial intelligence technologies, artificial neural networks (ANNs) are attracting more and more attention from specialists involved in forecasting electricity consumption.

Neural networks $(\mathrm{NN})$ are computational structures that simulate processes similar to those occurring in the human brain. Neural networks are distributed and parallel systems capable of adaptive learning by reacting to positive and negative influences. At the heart of building a network is an elementary transformer called an artificial neuron or simply a neuron by analogy with its biological prototype.

The structure of the neural network (Fig. 1) can be described as follows. The neural network consists of several layers: input, internal (hidden) and output. The input layer implements communication with the input data, the output layer - with the output. There can be one or more inner layers. Each layer contains several neurons. There are connections between neurons called weights. 


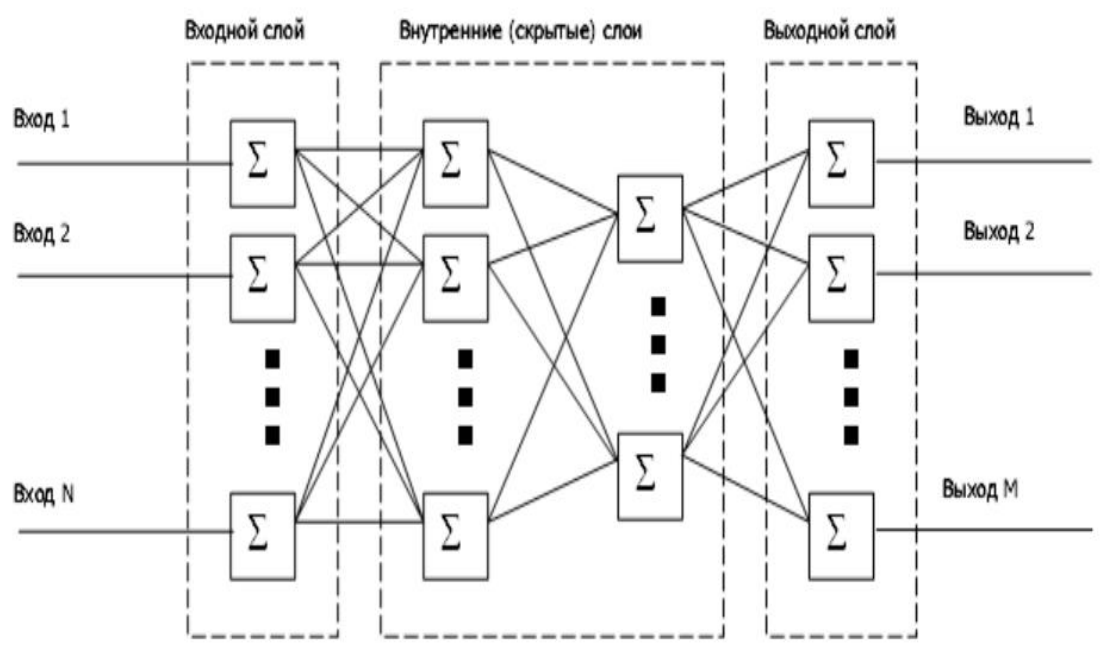

Fig. 1. The structure of the neural network.

When planning energy consumption, it is necessary to determine as accurately as possible the factors that influence the forecast. The attractiveness of the ANN application lies in the possibility of using a large number of different input parameters. Climatic conditions are of great importance for electricity consumption. Statistical analyzes have shown that temperature is the most important among the meteorological factors affecting the change in power consumption. The dependence of consumption on temperature is pseudo-linear. It is known that electricity consumption increases on cold days, when additional electric heaters are turned on, and on hot days, when air conditioners are turned on. Other meteorological factors are air humidity or wind speed, which create discomfort for humans and may explain the use of heating and cooling devices [12-15].

The length of the day is an important input parameter. As daylight shrinks, the use of electricity for many consumers increases. It is also influenced by the conversion of clocks from summer time to winter time and back

Social factors also influence energy consumption. These include: the number of working days and days off, holidays and shortened working days, vacations, etc.

When planning electricity consumption, the development trends of the enterprise should be taken into account. Consumption increases due to increased volumes of raw materials or the use of additional equipment. When carrying out preventive maintenance or stopping equipment, consumption falls. Consumption is greatly influenced by the tariff at which the company bills for electricity [16-18].

It is also worth noting that when predicting power consumption, it is necessary to take into account the specific parameters that are characteristic of the consumer. Each production contains individual technological cycles, which, when summed up, form a unique time process. However, in all production cycles of energy consumption, common features can be found, thereby forming a methodological basis for making an accurate forecast.
Let us consider an example of annual forecasting of workshop power consumption using neural networks included in the Matlab 7 (Neural Network Toolbox) package. The input parameters are taken as the average monthly temperature, the number of weekends and holidays per month, the average length of the day, the total installed capacity of the equipment used, the number of orders, the number of equipment used. The output parameter is the monthly electricity consumption in $\mathrm{kW}$.

Create a MLN with back propagation of an error: net $=$ newff([1 12; $-1820 ; 610 ; 1830 ; 517 ; 816 ; 7$. 18 ],[250 1], ... \{'tansig' 'purelin'\},'traincgf').

As shown, the network has 250 neurons and a tansig activation function on the first layer, as well as one neuron and a purelin activation function on the second. Training is set by the traincgf function [19-21].

We set the parameters for training the network: net.trainParam.epochs $=400 ;-$ maximum number of training cycles;

net.trainParam.goal $=1 \mathrm{e}-5$; - the limiting value of the learning criterion;

net.trainParam.lr $=0.1 ;-$ learning rate parameter;

net.trainParam.show $=5 ;-$ information display interval;

net.trainParam.mc $=1 ;-$ perturbation parameter.

The network training schedule is shown in Fig. 2, from which it can be seen that the given neural network is optimally trained and is suitable for predicting the power consumption of a given object. The neural network training schedule matches the initial consumption data.

Let's make a forecast, for which we set the network's estimated parameters for the next year (temperature, number of orders, etc.). The results are shown in Fig. 3.

Thus, using the current values of the parameters, a graph of the forecast of electricity consumption for the future period was obtained. The network was trained with a minimum error, which makes it possible to obtain the most accurate forecast [22-27]. 


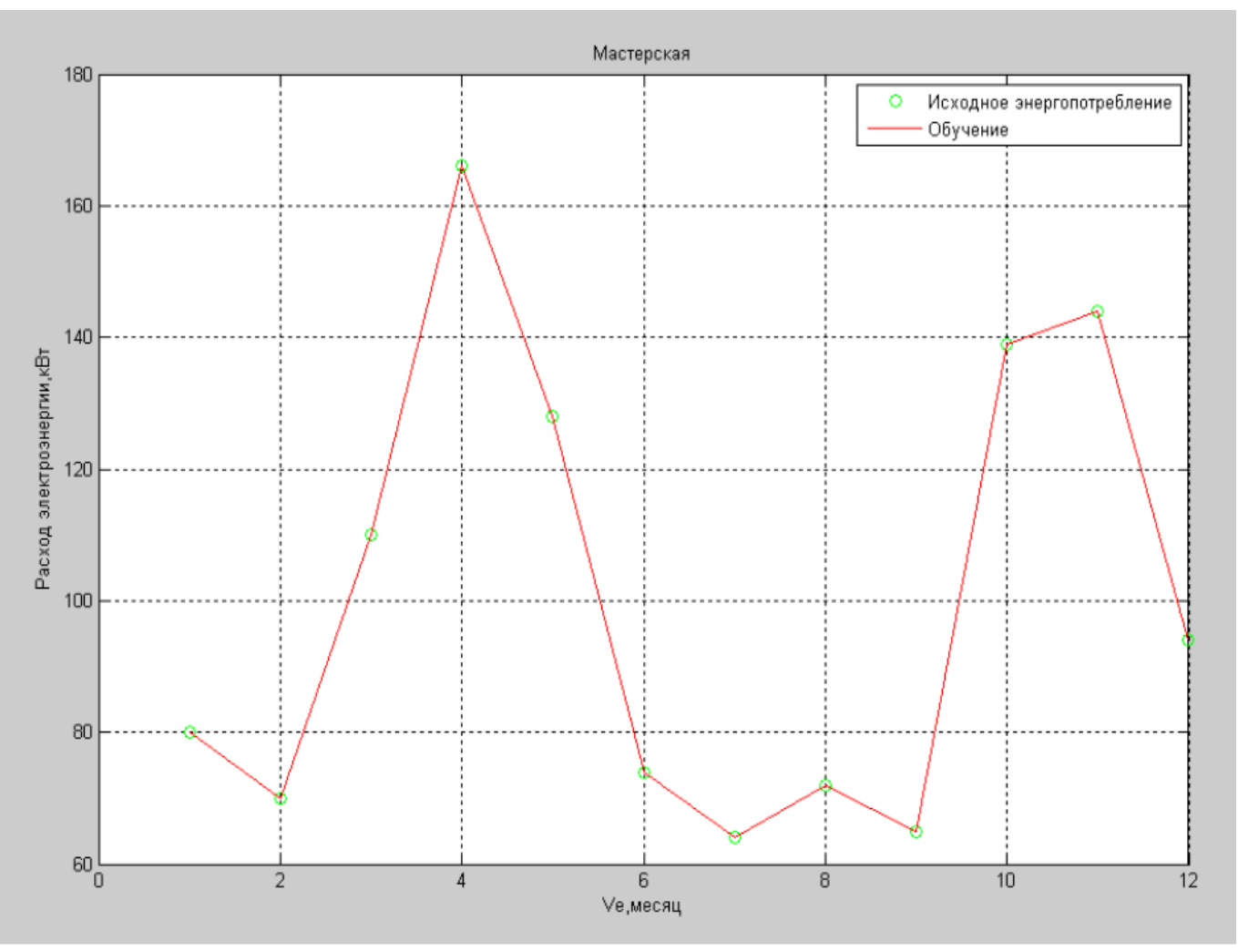

Fig. 2. Schedule of neural network training.

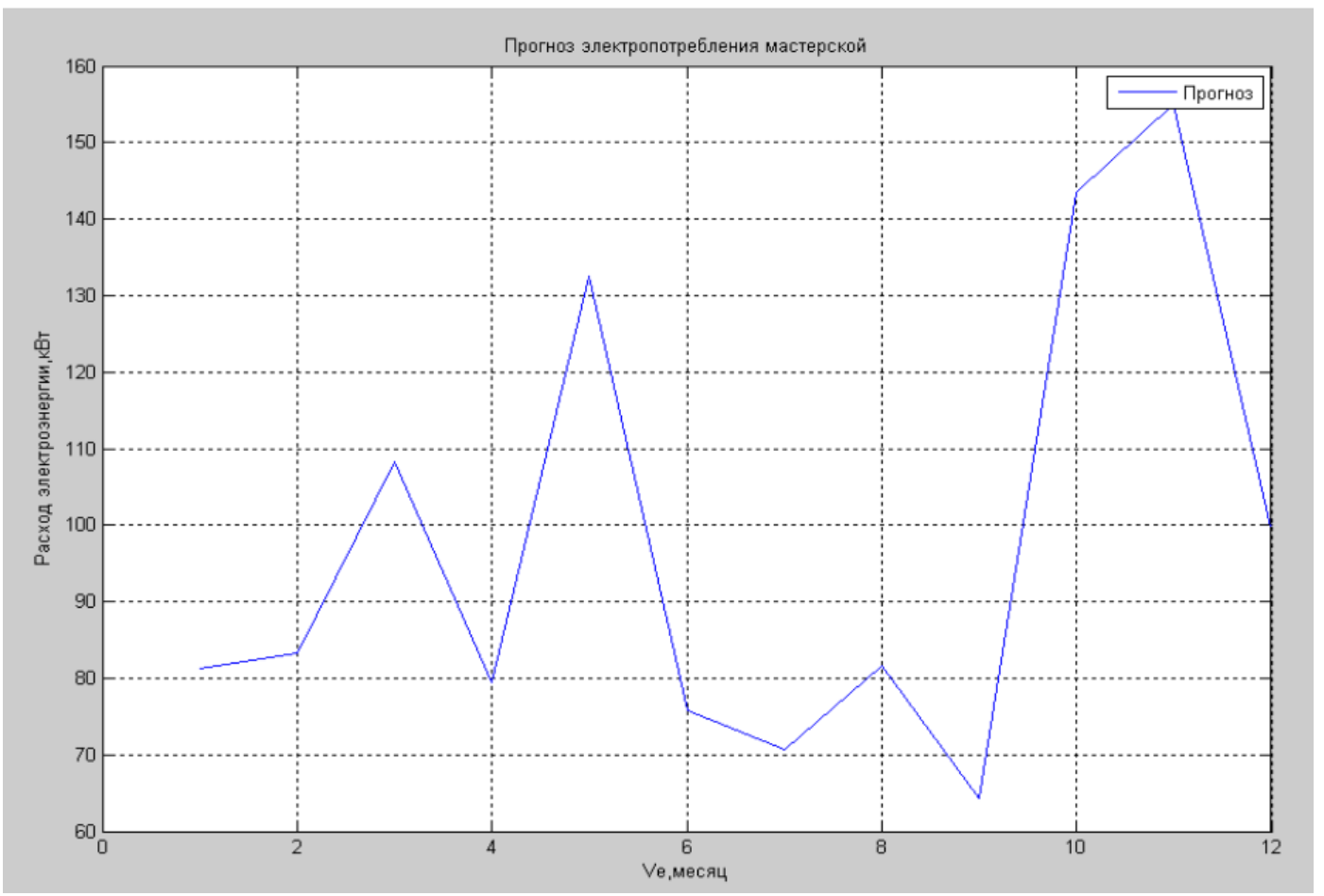

Fig. 3. Forecast of annual workshop power consumption. 


\section{Conclusions}

1. The use of artificial neural networks allows you to minimize the participation of an expert.

2. Neural networks allow you to take into account the main factors affecting the accuracy of the forecast, without limiting the input parameters.

3. The automated forecasting system makes it possible to estimate the forecasting error, to identify the parameters that affect the consumption of electricity.

\section{References}

1. Allayev, K.R., Fedorenko, G.M.,Postnikov, V.I.,Ostapchuk, L.B. Asynchronous generators as power system's natural dampers. 43rd International Conference on Large High Voltage Electric Systems 2010, CIGRE 20102010, 9p43rd International Conference on Large High Voltage Electric Systems 2010, CIGRE 2010; Paris; France; 22 August 2010.

2.Fazylov, Kh.F.,Allaev, K.R. Analysis of the operation of an electrical system during simultaneous operation of synchronous and asynchronous generators. Power engineering New York Volume 18, Issue 3, 1980, Pages 81-88.

3.Fazylov, Kh.F.,Allaev, K.R. Asynchronous turbogenerators with stator excitation and the prospects for their utilization. Power engineering New York Volume 23, Issue 2, 1985, Pages 7-13.

4.Fazylov, Kh.F.,Allaev, K.R. Calculation and experimental analysis of conditions of electrical power systems containing induction generators Power Engineering New York Volume 27, Issue 6, 1989, Pages 27-34.

5.Allaev K., Makhmudov T. Research of small oscillations of electrical power systems using the technology of embedding systems. Electrical Engineering, 2020; Issue 1: 309-319.DOI 10.1007/s00202-019-00876-9

6.Allaev K., Makhmudov T. Prospects of diversification and ensuring energy safety of Uzbekistan. E3S Web Conf., Volume 139, 2019, Rudenko International Conference "Methodological problems in reliability study of large energy systems" (RSES 2019).https://doi.org/10.1051/e3sconf/201913901002

7.Koptsev L A, Koptsev A L 2011 Rationing and forecasting of electricity consumption in an industrial enterprise $J$ Industrial power engineering. 1 pp 18-23 9.Toshniyozov, L.G., Toshov, J.B. Theoretical and experimental research into process of packing in drilling// Mining Informational and Analytical Bulletin Volume 2019, Issue 11, 2019, Pages 139-151. DOI: 10.25018/0236-1493-2019-11-0-139-151.

10. Saidkhodjaev A G, Najimova A M and Bijanov A K 2019 Method for determining the maximum load of consumers in city power supply systems E3S Web Conf 139 doi:10.1051/e3sconf/201913901078.

11. Taslimov A D, Rakhmonov I U 2019 Optimization of complex parameters of urban distribution electric networks Journal of Physics: Conference Series 1399 doi:10.1088/1742-6596/1399/5/055046
12. Safarov J E, Sultanova Sh A, Dadayev G T and Samandarov D I 2019 Method for drying fruits of rose hips International Journal of Innovative Technology and Exploring Engineering 9 pp 3765-3768 DOI: 10.35940/ijitee.A4716.119119

13. Toshov, Zh.B. Ways towards optimization of washout components of rock cutting tools Information about author // Gornyi Zhurnal. Volume 2016, Issue 2, 1 January 2016, Pages 21-24.

14. Rakhmonov I U, Niyozov N N 2019 Optimization setting of steel-smelting industry in the issue of alloy $\begin{array}{llll}\text { steels } & \text { E3S } & \text { Web } & \text { Conf }\end{array}$ doi:10.1051/e3sconf/201913901077

15. Safarov J E, Sultanova Sh A, Dadayev G T and Samandarov D I 2019 Method for the primary processing of silkworm cocoons (Bombyx mori) International Journal of Innovative Technology and Exploring Engineering 9 pp $4562-4565$ DOI: 10.35940/ijitee.A5089.119119

16. Rakhmonov I U, Reymov K M and Shayumova Z M 2019 The role information in power management tasks. E3S Web Conf 139 doi:10.1051/e3sconf/201913901080 17. Sultanova Sh A, Safarov J E2020 Experimental study of the drying process of medicinal plants International Journal of Psychosocial Rehabilitation 24 pp 1962-1968 DOI: $10.37200 /$ IJPR/V24I8/PR280216

18. Rakhmonov I U, Reymov K M 2019 Mathematical Models and Algorithms of Optimal Load Management of Electricity Consumers J ENERGETIKA. Proceedings of CIS higher education institutions and power engineering association 62(6) pp 528-535 doi:10.21122/1029-7448-2019-62-6-528-535

19. Mannanov U., Toshov J., Toshniyozov L. Perspective Solutions for the Design of Drilling Tools / E3S Web of Conferences 105, 03027 (2019) IVth International Innovative Mining Symposium, https://doi.org/10.1051/e3sconf/201910503027

20. Rakhmonov I U, Tovbaev A N, Nematov L A and Alibekova T Sh 2020 Development of forecasted values of specific norms for the issues of produced products in industrial enterprises Journal of Physics: Conference Series 1515 doi:10.1088/1742-6596/1515/2/022050

21. Burievich, T.J. The questions of the dynamics of drilling bit on the surface of well bottom// Arch. Min. Sci. -Poland. - Vol. 61 (2016). - №2. - P. 279-287. DOI 10.1515/amsc-2016-0020.

22. Rakhmonov I U, Nematov L A, Niyozov N N, Reymov K M and Yuldoshev T M 2020 Power consumption management from the positions of the general system theory Journal of Physics: Conference Series 1515 doi:10.1088/1742-6596/1515/2/022054

23. Rakhmonov I U, Reymov K M 2019 Regularities of change of energy indicators of the basic technological equipment of the cotton-cleaning industry Journal of Physics: Conference Series 1399 doi:10.1088/17426596/1399/5/055038

24. Avezova N.R., Toshov J.B., Dalmuradova N.N., Farmonova A.A., Mardonova M.Sh.Renewable Energy: Scenario and Model of Development // ISSN 0003701X, Applied Solar Energy, 2019, Vol. 55, No. 6, pp. 438-445. DOI: 10.3103/S0003701X19060021 
25. Taslimov A D, Berdishev A S, Melikuzuev M V and Rakhimov F M 2019 Method of selecting parameters of cable lines distributive networks $10 \mathrm{kv}$ in uncertainty $\begin{array}{llll}\text { conditions } & \text { E3S } & \text { Web }\end{array}$ doi:10.1051/e3sconf/201913901082

26. Azamatovich, A.N., Amrillo, M.B, Burievich, T.J., Umarxanoxich, J.R., Shavkatovich, Z.A. A complex of methods for analyzing the working fluid of a hydrostatic power plant for hydraulic mining machines / International Journal of Advanced Science and Technology. Volume 29, Issue 5 Special Issue, 28 March 2020, Pages 852-855

27. Khakimov H T, Shayumova Z M, Kurbanbaeva Z Kh and Khusanov B M 2019 Development of optimal modes and mathematical models of energy performance of electric steelmaking production . E3S Web Conf 139 doi:10.1051/e3sconf/201913901076 